\title{
Subclinical hepatic encephalopathy in cirrhotic patients: Prevalence and relationship to liver function
}

\author{
Gilles Pomier-Layrargues, MD, Ngoc HuU Nguyen, Claire Faucher, MA, \\ Jean-Françols GIGUĖre, PhD, MD, Roger F BUtTER WORTH, PHD
}

G POMIER-Layrargues, NH NGUyen, C FAucher, J-F Giguère, RF BUTTERWORTH. Subclinical hepatic encephalopathy in cirrhotic patients: Prevalence and relationship to liver function. Can J Gastroenterol 1991;5(4): 121-125. Neuropsychological tests were administered to 22 alcoholic cirrhotic patients, 20 nonalcoholic cirrhotic patients and 42 control subjects matched for age and educational background. Liver function estimated by Pugh score was identical in alcoholic and nonalcoholic cirrhotics. Thirty-two cirrhotic patients (76\%) failed one or more psychological test. Performance was worse in cirrhotics than in controls in all but one test: the degree of neurological impairment was similar in alcoholics and nonalcoholics and correlation with the severity of liver dysfunction was only marginal. A combination of the five more sensitive tests was able to identify 31 of 32 cirrhotic patients with subclinical encephalopathy; this 'mini battery' of tests can be performed within 10 mins. Subclinical hepatic encephalopathy is frequent in cirrhotic patients and can adversely affect their psychosocial behaviour.

Key Words: Hepatic encephalopathy, Liver cirrhosis, Psychometric tests

\section{Encéphalopathie hépatique subclinique chez les cirrhotiques: Prévalence et liens avec les fonctions hépatiques}

RESUME: Vingt-deux cirrhotiques alcooliques, 20 cirrhotiques non alcooliques et 42 sujets témoins ont été appariés en fonction de l'âge et de l'éducation, et ont subi des tests neuropsychologiques. Les fonctions hépatiques estimées selon

Liver Unit, Psychology Unit and Laboratory of Neurochemistry, Saint-Luc Hospital and André-Viallet Clinical Research Centre, University of Montreal, Montreal, Quebec

Correspondence and reprints: Dr Gilles Pomier-Layrargues, André-Viallet Clinical Research Centre, 264, René-Lévesque est, Montréal, Québec H2X IP1. Telephone (514) 281-2461, Fax (514) 281-2492

Received for publication March 11, 1991. Accepted May 25, 1991
$\mathrm{H}$ EPATIC ENCEPHALOPATHY IS usually classified into four stages according to the severity of neurological symptoms. However, it is now well recognized that a significant proportion of cirrhotic patients show subtle neurological deficits that are not detectable via routine neurological examination but can be demonstrated via either neuropsychological tests or visually evoked potentials (1). This entity is generally referred to as subclinical hepatic encephalopathy. Its prevalence is variable depending on the patient population and on the battery of tests used to detect it. It is now established that subclinical hepatic encephalopathy may occur in both alcoholic and nonalcoholic cirrhotic patients (2-6). However, the relationship between neuropsychological impairment and liver function is still controversial $(2,3)$.

The present study was designed to evaluate in a Canadian population of cirrhotic patients the prevalence of subclinical hepatic encephalopathy and the relationship between subclinical hepatic encephalopathy and liver 
l'indice de Pugh étaient identiques chez les cirrhotiques alcooliques et non alcooliques. Trente-deux patients cirrhotiques $(76 \%)$ ont échoué à au moins un test psychologique. Pour tous les examens sauf un, la performance était pire parmi les cirrhotiques que dans le groupe témoin; le degré de déficit neurologique était semblable chez les alcooliques et les non-alcooliques, et la corrélation avec la gravité de l'atteinte hépatique n'était que marginale. Un ensemble de cinq tests plus perfectionnés a permis d'établir que 31 des 32 cirrhotiques souffraient d'une encéphalopathie subclinique; cette 'mini- batterie' de tests peut être effectuée en moins de 10 minutes. L'encéphalopathie hépatique subclinique est fréquente chez les cirrhotiques et peut perturber leur comportement psychosocial. function. Moreover, the authors have designed a 'mini battery' of neuropsychological tests that can be administered quickly by a physician working in general practice.

\section{PATIENTS AND METHODS}

Subjects: Forty-two patients with biopsy-proven liver cirrhosis were evaluated as in-or outpatients: 22 had cirrhosis secondary to chronic alcoholism (daily ingestion of $100 \mathrm{~g}$ ethanol for more than 10 years) and 20 had nonalcoholic cirrhosis (four, primary biliary cirrhosis; seven, hepatitis B viral cirrhosis; three, hepatitis C viral cirrhosis; and six, cryptogenic cirrhosis). All of the alcoholics had been abstinent for at least two months. Three patients had had previous end-to-side portacaval shunt surgery. Hepatic function was evaluated using the Pugh score (7).

The control group was composed of 37 patients admitted for various nonhepatic diseases and five healthy volunteers. Alcoholics as well as patients with other neurological or psychiatric disease were excluded, as were patients on medication (particularly sedatives and narcotic analgesics) which might influence the neuropsychological parameters to be studied.

Neuropsychological tests: Routine neurological evaluation of all subjects (cirrhotics and controls) was found to be normal. Mental status was assessed by evaluating alertness, orientation as to time, space, persons and language, and ability to name the three past premiers of the province of Quebec.

\section{TABLE 1}

\section{Demographic data in cirrhotic and control groups}

\begin{tabular}{lcccc}
\hline & $\begin{array}{c}\text { Controls } \\
(n=42)\end{array}$ & Alcoholic $(n=22)$ & $\begin{array}{c}\text { Cirrhotics } \\
\text { Nonalcoholic }(n=20)\end{array}$ & Both $(n=42)$ \\
\hline Age (years) & $50 \pm 11$ & $53.4 \pm 8.7$ & $53.5 \pm 8.2$ & $53.4 \pm 8.4$ \\
& $(23$ to 71$)$ & $(30$ to 70$)$ & $(42$ to 72$)$ & $(30$ to 72$)$ \\
Education & $9.6 \pm 3.9$ & $8.6 \pm 3.5$ & $9.1 \pm 3.7$ & $8.8 \pm 3.5$ \\
(years) & $(4$ to 20$)$ & $(4$ to 20$)$ & $(4$ to 18$)$ & $(4$ to 20$)$ \\
\hline
\end{tabular}

Values given are mean \pm standard deviation. Values in parentheses are range. There was no significant difference between demographic parameters from controls versus cirrhotics or from alcoholic versus nonalcoholic cirrhotics

\section{TABLE 2}
Clinical and biochemical parameters in cirrhotic patients (mean \pm standard deviation)

\begin{tabular}{lcc}
\hline & Alcoholics & Nonalcoholics \\
\hline Ascites, incidence & $10 / 22$ & $10 / 22$ \\
Serum bilirubin $(\mu \mathrm{mol} / \mathrm{L})$ & $78.0 \pm 123$ & $81 \pm 157$ \\
Serum albumin $(\mathrm{g} / \mathrm{L})$ & $27.8 \pm 5.9$ & $25.8 \pm 66$ \\
Prothrombin time $(\mathrm{s}$ above control) & $4.1 \pm 2.4$ & $3.2 \pm 2.2$ \\
Pugh score & $8.5 \pm 2.3$ & $8.5 \pm 2.2$ \\
\hline
\end{tabular}

There was no significant difference between the two groups for any of the above parameters
None of the patients had asterixis and handwriting was normal.

Neuropsychological tests were performed by a physician as a simple observer and required 20 to $30 \mathrm{mins}$. They were selected in order to evaluate nonverbal functions $(8,9)$ and consisted of the following:

Delayed recall. The patient is asked if he or she can recall three words given to him 10 mins previously.

Attention and concentration. Serial threes: The patient is asked to begin with one and count forward by threes to 100 . Arithmetic: The patient is asked to perform mentally eight calculations of increasing difficulty. Months backward: The patient is asked to name the months of the year in reverse order starting with December. Digit span forward and backward: The digit span tests the number of digits the patient is able to recall immediately from memory from a previously given list. Alphabet: The time needed to enumerate the letters of the alphabet is measured.

Visuospatial ability. The patient is asked to make a drawing of a clock indicating a fixed time ( 10 mins past 11 o'clock). Psychomotor speed. Digit symbol: The subject must associate one set of symbols with another set of numbers. Reitan trail making tests: The subject must connect in order a series of either numbers (part A) or numbers and letters (part B) randomly presented.

\section{STATISTICS}

The results of individual tests were considered abnormal if they fell outside the range of two standard deviations above the mean value in control patients. Data were also compared between controls and cirrhotics, and between alcoholic and nonalcoholic cirrhotics using Student's $t$ test for unpaired data. Correlations were evaluated with the Spearman rank correlation test.

\section{RESULTS}

Control patients and cirrhotics were strictly matched for age and educational background (Table 1). Among the cirrhotic patients, nine were in Pugh class A (score 5 to 6), 18 were in Pugh class B (score 7 to 9) and 15 were in 
TABLE 3

Results of neuropsychological tests in control subjects and cirrhotic patients (mean \pm standard deviation)

\begin{tabular}{|c|c|c|c|c|}
\hline Test & $\begin{array}{l}\text { Controls } \\
(n=42)\end{array}$ & Alcoholic $(n=22)$ & $\begin{array}{c}\text { Cirrhotics } \\
\text { Nonalcoholic }(n=20)\end{array}$ & Total $(n=42)$ \\
\hline Delayed recall (number of words) & $2.7 \pm 0.5$ & $2.2+0.9^{*}$ & $2.3 \pm 0.9^{*}$ & $2.2 \pm 0.9^{*}$ \\
\hline Arithmetic (number of errors) & $0.6 \pm 0.9$ & $2.5 \pm 1.9^{*}$ & $2.2 \pm 1.9^{*}$ & $2.3 \pm 1.9^{*}$ \\
\hline Months backward (s) & $14 \pm 6$ & $33 \pm 34^{*}$ & $28 \pm 30$ & $31 \pm 32^{*}$ \\
\hline Digit span forward (number) & $6.5 \pm 1.2$ & $5.7 \pm 1.1^{\circ}$ & $5.9 \pm 1.2^{*}$ & $5.8 \pm 1.1^{\circ}$ \\
\hline Digit symbol (number) & $39.6 \pm 11.4$ & $25.7 \pm 8.3^{*}$ & $27.7 \pm 10.2^{*}$ & $26.7 \pm 9.2^{\circ}$ \\
\hline \multicolumn{5}{|l|}{ Reitan trail making tests } \\
\hline Part A (s) & $38.9 \pm 13.5$ & $61.6 \pm 24.3^{\circ}$ & $59.7 \pm 22.1^{*}$ & $60.7 \pm 23.0^{*}$ \\
\hline Part B (s) & $83.9 \pm 31.8$ & $140.1 \pm 50.1^{\circ}$ & $153.5 \pm 50.2^{*}$ & $146.5 \pm 50.0^{*}$ \\
\hline Clock drawing (normal/abnormal) & $40 / 2$ & $17 / 5$ & $16 / 4$ & $33 / 9$ \\
\hline
\end{tabular}

Significantly different from control group $(P<0.01)$; no significant difference could be found between alcoholic and nonalcoholic cirrhotic patients

Pugh class C (score 10 to 15 ). Comparisons between alcoholic and nonalcoholic cirrhotic patients showed that the severity of liver dysfunction was similar in these two groups (Table 2).

Results of neuropsychological tests for alcoholic and nonalcoholic cirrhotic patients were not significantly different.

Results of individual neuropsychological tests are summarized in Table 3. Thirty-two cirrhotic patients failed one test $(76 \%)$ and 22 failed two tests (52\%). Overall the performance of cirrhotic patients was significantly worse than that of controls in all tests except for clock drawing. The most sensitive test to detect subclinical hepatic encephalopathy in cirrhotic patients was the Reitan trail making test part B (48\% abnormal results) (Table 4). When using a mini battery of the five most sensitive tests (Reitan trail making tests part $\mathrm{A}$ and $\mathrm{B}$, months backward, alphabet and arithmetic), the authors were able to detect 31 of 32 patients found to have subclinical hepatic encephalopathy.

The authors also evaluated the relationship between individual neuropsychological tests and serum albumin, serum bilirubin, prothrombin time and Pugh score. The only significant correlations found were between the Reitan trail making test part $\mathrm{B}$ and both serum albumin $(r=0.35 ; \mathrm{P}<0.05)$ and the Pugh score $(r=0.37 ; \mathrm{P}<0.05)$.

TABLE 4

Sensitivity of neuropsychological tests in detecting subclinical hepatic encephalopathy in cirrhotic patients

\begin{tabular}{lcc}
\hline Test & $\begin{array}{c}\text { Abnormal tests in cirrhotic patients } \\
\text { Number }\end{array}$ \\
\hline Reitan trail making test (part B) & $20 / 42$ & $48 \%$ \\
Alphabet & $17 / 42$ & $40 \%$ \\
Months backward & $14 / 42$ & $33 \%$ \\
Arithmetic & $14 / 42$ & $33 \%$ \\
Reitan trail making test (part A) & $13 / 42$ & $31 \%$ \\
Digit span backward & $10 / 42$ & $24 \%$ \\
Serial threes & $8 / 42$ & $19 \%$ \\
Digit symbol & $8 / 42$ & $19 \%$ \\
Digit span forward & $4 / 42$ & $10 \%$ \\
\hline
\end{tabular}

\section{DISCUSSION}

The present study reveals subtle impairment in neuropsychological performance in a large percentage of cirrhotic patients in the absence of overt neurological abnormalities. Seventy-six per cent of cirrhotic patients had subclinical hepatic encephalopathy demonstrated by abnormalities in one or more tests. This prevalence was comparable with that previously reported (1).

Comparison of the cirrhotic group with a control group strictly matched for age and educational background was performed in order to avoid any influence of these parameters on the performance of the tests used. A battery of tests was chosen which had previously been reported to be sensitive and which was easily and quickly ad- ministered; in the present study, neuropsychological testing took 30 mins. The mini battery on the other hand could be administered in 10 mins. This latter evaluation could be easily performed by a general practitioner. This approach contrasts with the vast majority of previous reports which used a complex battery of tests often requiring the assistance of a clinical psychologist and taking 2 to $3 \mathrm{~h}$ to perform.

The Wechsler adult intelligence scale and the Reitan trail making tests were used in most of the previous studies. Reitan trail making tests part A or $\mathrm{B}$ used alone or in combination with the block design tests were repeatedly reported to be most sensitive $(2-6,10$. 12); some authors suggested measurement of continuous reaction time (13). 
It has also been suggested that visual evoked potentials or somatosensory evoked potentials could be useful in detecting subclinical hepatic encephalopathy (14-17). However, their specificity is questionable and their efficacy is probably not better than that of simple neuropsychometric tests (15). The authors observed that the most sensitive tests were the Reitan trail making test part B followed by alphabet, months backward, arithmetic and the Reitan trail making test part A.

This study also demonstrates that subclinical hepatic encephalopathy occurs in alcoholics as well as nonalcoholics, which confirms results obtained by other groups in recent years (2-6). This finding demonstrates that liver disease per se may induce alterations in neuropsychological performance. The question then arises as to whether the severity of neurological abnormalities is correlated with the degree of liver failure per se. Previous studies have generally suggested that there is no relationship between these

\section{REFERENCES}

1. Gitlin N. Subclinical portal-systemic encephalopathy. Am J Gastroenterol 1988;83:8-11.

2. Gilberstadt SJ, Gilberstadt H, Zieve L, Buegel B, Collier RO, McClain CJ. Psychomotor performance defects in cirrhotic patients without overt encephalopathy. Arch Intern Med 1980;140:519-21.

3. Gitlin N, Lewis DC, Hinkley L. The diagnosis and prevalence of subclinical hepatic encephalopathy in apparently healthy, ambulant, non-shunted patients with cirrhosis. J Hepatol 1986;3:75-82.

4. Rehnstrom S, Simert G, Hansson JA, Johnson G, Vang J. Chronic hepatic encephalopathy. A psychometrical study. Scand J Gastroenterol 1977; 12:305-11.

5. Smith HH, Sikorki-Smith L. WAIS functioning of cirrhotic and noncirrhotic alcoholics. J Clin Psychol 1977;33:309-13.

6. Sood GK, Sarin SK, Mahaptra J, Brook SL. Comparative efficacy of psychometric tests in detection of subclinical hepatic encephalopathy in non alcoholic cirrhotics: Search for a rational approach. Am J Gastroenterol 1989;84:156-9. two parameters $(3,18)$. However, one paper reported a correlation between abnormal performance in tests and serum albumin (2). In the present study, serum albumin and Pugh score demonstrated a small but significant correlation with one test, the Reitan trail making test part $\mathrm{B}$. This finding is not surprising as the occurrence of subclinical hepatic encephalopathy is probably related not only to liver function but also to the extent of spontaneous or surgically induced portal systemic shunting. Unfortunately this latter parameter could not be evaluated in the present patients.

The fact that a majority of cirrhotic patients without overt hepatic encephalopathy display impairment in psychomotor performance has several practical implications. First, these deficits may affect the way of life of many patients, particularly if their work necessitates intellectual activity or precise mechanical manipulations. The problem of impairment in driving capacity was also addressed several years ago (19). Second, these abnor-

7. Pugh RNH, Murray-Lyon IM, Dawson JL, Pietroni MC, Williams R. Transection of the oesophagus for bleeding oesophageal varices. Br J Surg 1973;60:646-9.

8. Kaplan E. A process approach to neuropsychological assessment. In: Boll T, Bryant BK, eds. Clinical Neuropsychology and Brain Function: Research, Measurement and Practice. Master Lecturers. Washington, DC: American Psychology Association, 1988:125-67.

9. Lezak MD. Neuropsychological Assessment, 2nd edn. New York: Oxford University Press, 1983.

10. Loguercio C, Del Vecchio-Blanco C, Coltorti M. Psychometric tests and latent portal-systemic encephalopathy. Br J Clin Pract 1984;38:407-11.

11. Tarter RE, Hegedus AM, Van Thiel DH, Shade RR, Gavaler JS, Starzl TE. Non alcoholic cirrhosis associated with neuropsychological dysfunction in the absence of overt evidence of hepatic encephalopathy. Gastroenterology 1984;84:1421-7.

12. Zeegen R, Drinkwater JE, Dawson AM. Methods for measuring cerebral dysfunction in patients with liver disease. Br Med J 1970;2:633-6.

13. Elsass P, Christensen SE, Ranek L, malities are almost entirely reversible according to a recent study which demonstrated that almost all neuropsychological abnormalities normalized following liver transplantation (20). This is somewhat surprising because several papers showed significant (presumably permanent) morphological abnormalities via computed tomo. graphy scan of the brains of cirrhotic patients with subclinical hepatic en. cephalopathy $(21,22)$. This issue clearly merits further study.

In summary, subclinical hepatic encephalopathy can be easily detected and quantitated in patients with chronic liver disease in 10 mins using simple tests. Results of the present study reveal a high prevalence of subclinical hepatic encephalopathy in cirrhotic patients.

Further studies are required to assess the effect of dietary manipulation or drugs used in the treatment of overt hepatic encephalopathy (lactulose, neomycin, metronidazole), for the treatment of subclinical hepatic encephalopathy in these patients.

Theilgaard A, Tygstrup N. Continuous reaction time in patients with hepatic encephalopathy: A quantitative measure of changes in consciousness. Scand J Gastroenterol 1981;16:441-7.

14. Levy LJ, Bolton RP, Losowsky MS.

The use of the visual evoked potentials (VEP) in delineating a state of subclinical encephalopathy. J Hepatol 1987;5:211-7.

15. Sandford NL, Saul RE. Assessment of hepatic encephalopathy with visual evoked potentials compared with conventional methods. Hepatology 1988;8:1094-8.

16. Weissenbor NK, Scholz M, Hinrichs H, Wiltfang J, Schmidt FW, Kunkel H. Neurophysiological assessment of early hepatic encephalopathy.

Electroenceph Clin Neurophysiol 1990;75:289-95.

17. Yen CL, Liaw YF. Somatosensory evoked potentials and number connection test in the detection of subclinical hepatic encephalopathy. Hepatogastroenterology 1990;37:332-4.

18. Rikkers LR, Jenko P, Rudman D, Freides D. Subclinical hepatic encephalopathy: Detection, prevalence and relationship to nitrogen metabolism. Gastroenterology $1978 ; 7: 462-9$. 
19. Shomerus H, Hamster W, Blunck H, Reinhard U, Mayer K, Dolle W.

Latent portosystemic encephalopathy. Nature of cerebral dysfunction defects and their effect on fitness to drive.

Dig Dis Sci 1981;26:622-30.

20. Tarter RE, Switala J, Arria A, Plail J, Van Thiel DH. Subclinical hepatic encephalopathy. Comparison before and after orthotopic liver transplantation. Transplantation 1990;50:632-7.

21. Bernthal P, Hays A, Tarter RE, Van Thiel D, Lecky J, Hegedus A. Cerebral CT-scan abnormalities in cholestatic and hepatocellular disease and their relationship to neuropsychologic test performance. Hepatology 1987;7:107-14.

22. Tarter RE, Hays AL, Sandford SS, Van Thiel DH. Cerebral morphological abnormalities associated with non alcoholic cirrhosis. Lancet 1986;ii:893-5. 


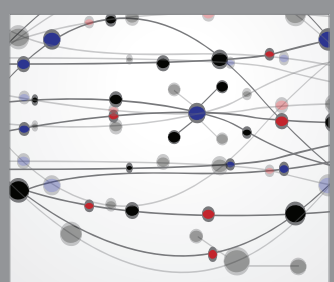

The Scientific World Journal
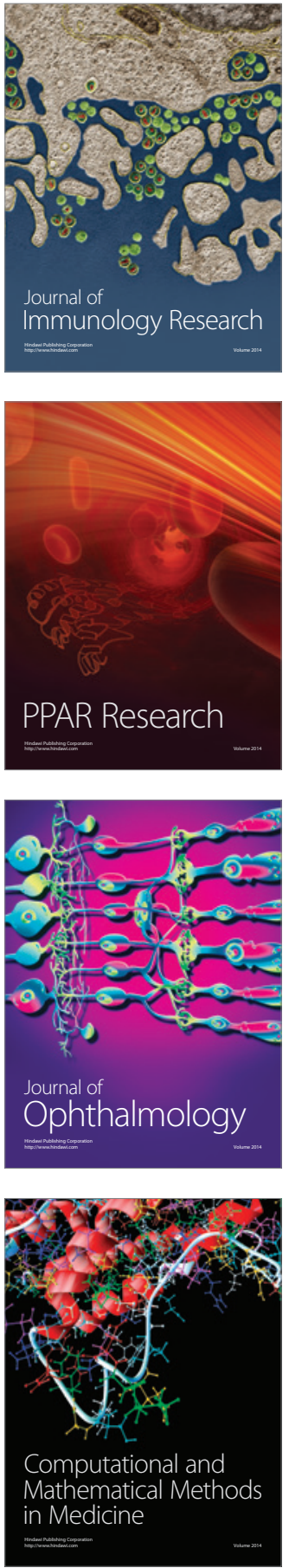

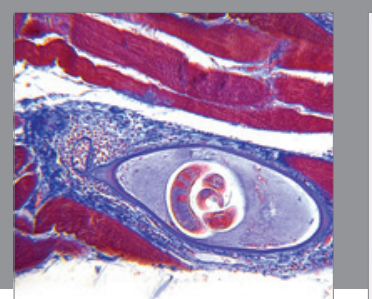

Gastroenterology Research and Practice

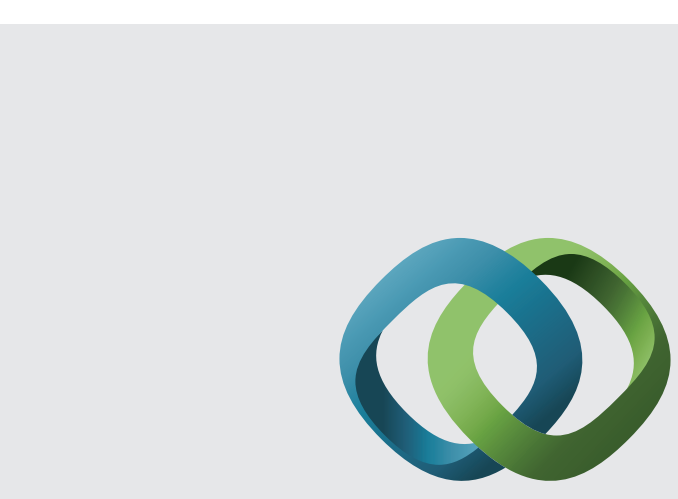

\section{Hindawi}

Submit your manuscripts at

http://www.hindawi.com
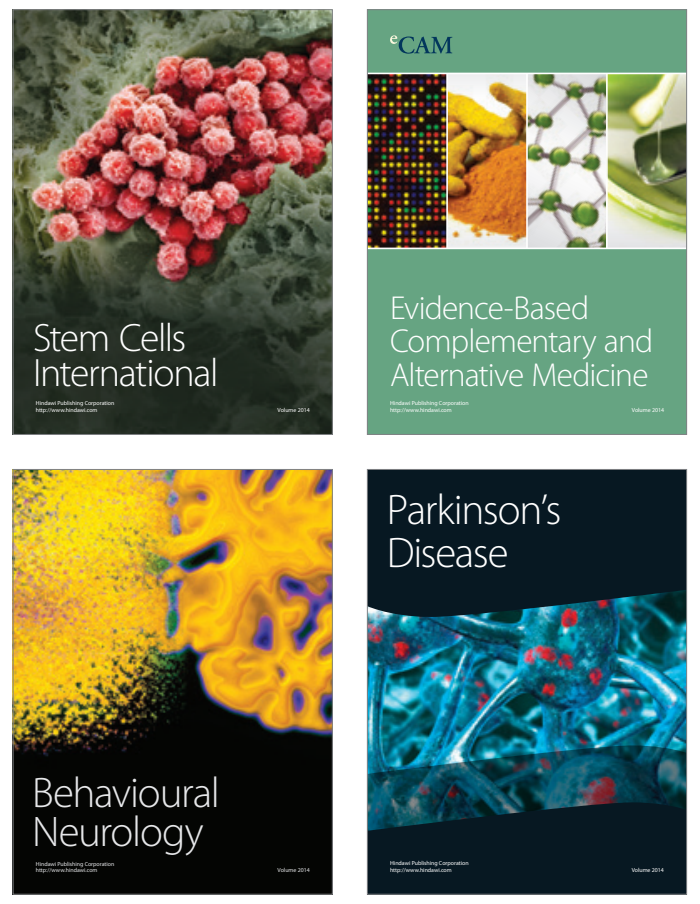
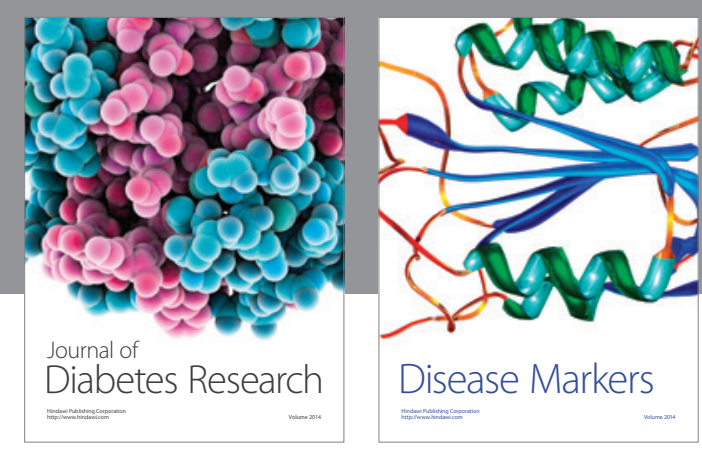

Disease Markers
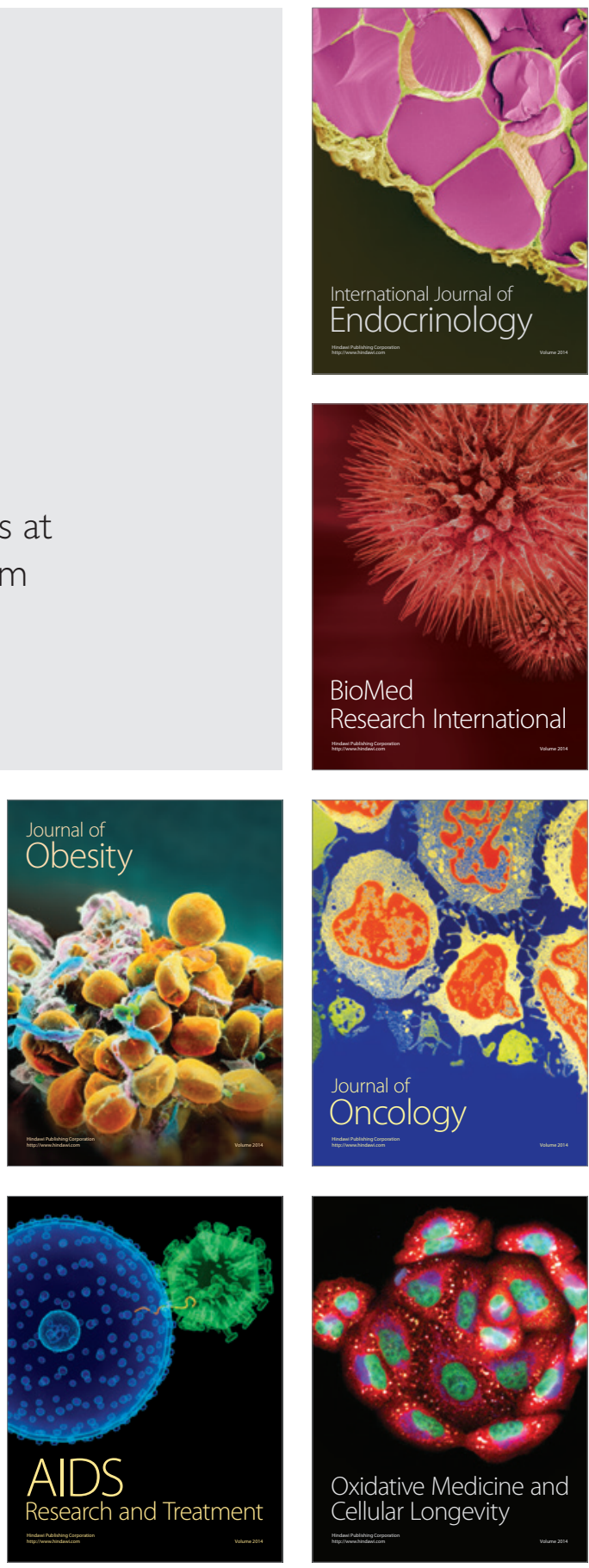